\title{
Seismic Prediction While Drilling (SPWD): Looking Ahead of the Drill Bit by Application of Phased Array Technology
}

\author{
by Katrin Jaksch, Rüdiger Giese, Matthias Kopf, Andreas Jurczyk, \\ Stefan Mikulla, Stefan Weisheit, Marco Groh, and Kay Krüger
}

\section{Introduction}

Geophysical exploration is indispensable for planning deep drilling. Usually $2 \mathrm{D}$ - or $3 \mathrm{D}$-seismics investigations are applied and, depending on the resulting geologic model for the underground, the drill site and drilling path are determined. In recent years the focus of exploration has shifted towards small-scale geological structures such as local layers and faults. Depending on the source frequencies and the target depth, 2D- or 3D-seismics from surface cannot always resolve such structures in particular at larger depths. In general, signal frequencies of about $30-70 \mathrm{~Hz}$ are typical for surface seismic methods. The deeper and smaller the sought-after structures are, the worse will be the resolution. Therefore, borehole seismic measurements like Vertical Seismic Profile (VSP) or Seismic While Drilling (SWD) have been developed (Fig. 1). For the VSP method geophones are normally integrated in the borehole, while the seismic source generates seismic waves at the surface. The SWD method uses the drill bit as the seismic source. Hence, the quality of the seismic signals is highly dependent on the drilled rock and the type of drill bit, but even well-suited rock conditions and adequate drilling may not provide sufficient data quality.
Compared to 2D- and 3D-seismics, the distances between source and receiver to the target are shorter for VSP, and for SWD in particular. Signal frequencies up to about $100 \mathrm{~Hz}$ are observed yielding a slightly better resolution compared to surface seismics. However, subtle yet important features (e.g., fault zone) often cannot be identified with certainty. Accordingly, a method or tool that would improve the resolution is of high importance since this would allow adjusting the drilling path to minimize risks and costs of drilling.

A device combining source and receiver immediately behind the drill bit would allow seismic exploration of a range of about 50-100 $\mathrm{m}$ ahead of the drill bit with a resolution of one meter. The first prototype of such a Seismic Prediction While Drilling (SPWD) device has been designed and manufactured within this project (Wenke et al., 2010). The tool uses signal frequencies between $500 \mathrm{~Hz}$ and $5000 \mathrm{~Hz}$, which are significantly higher than the usual VSP and SWD applications.

\section{A Laboratory Prototype for Seismic Prediction in Boreholes}

A SPWD prototype was designed for laboratory conditions without the impact of borehole fluids, high temperatures, and pressures and only for tests in horizontal boreholes. It consists of different units for seismic sources, receivers, and data logger. Figure 2 and Table 1 provide details of the instrumentation and dimensions. Four standard magnetostrictive actuators (AK1 to AK4; Fig. 2) are aligned along the borehole axis to serve as a cascading source and act as seismic sources. Every single actuator unit can be rotated in steps of $15^{\circ}$ around the longitudinal axis of the prototype to allow for a variety of source configurations trials.

Table 1. Parameters of the prototype
\begin{tabular}{|l|l|}
\hline Length & $1.81 \mathrm{~m}$ \\
\hline Diameter & $20-23.5 \mathrm{~cm}$ \\
\hline Weight & $\sim 60 \mathrm{~kg}$ \\
\hline Pressing & pneumatic, 6-8 bar \\
\hline Contact pressure: & \\
\hline actuators & $\sim 2 \mathrm{kN}$ \\
\hline geophones & $\sim 200 \mathrm{~N}$ \\
\hline
\end{tabular}




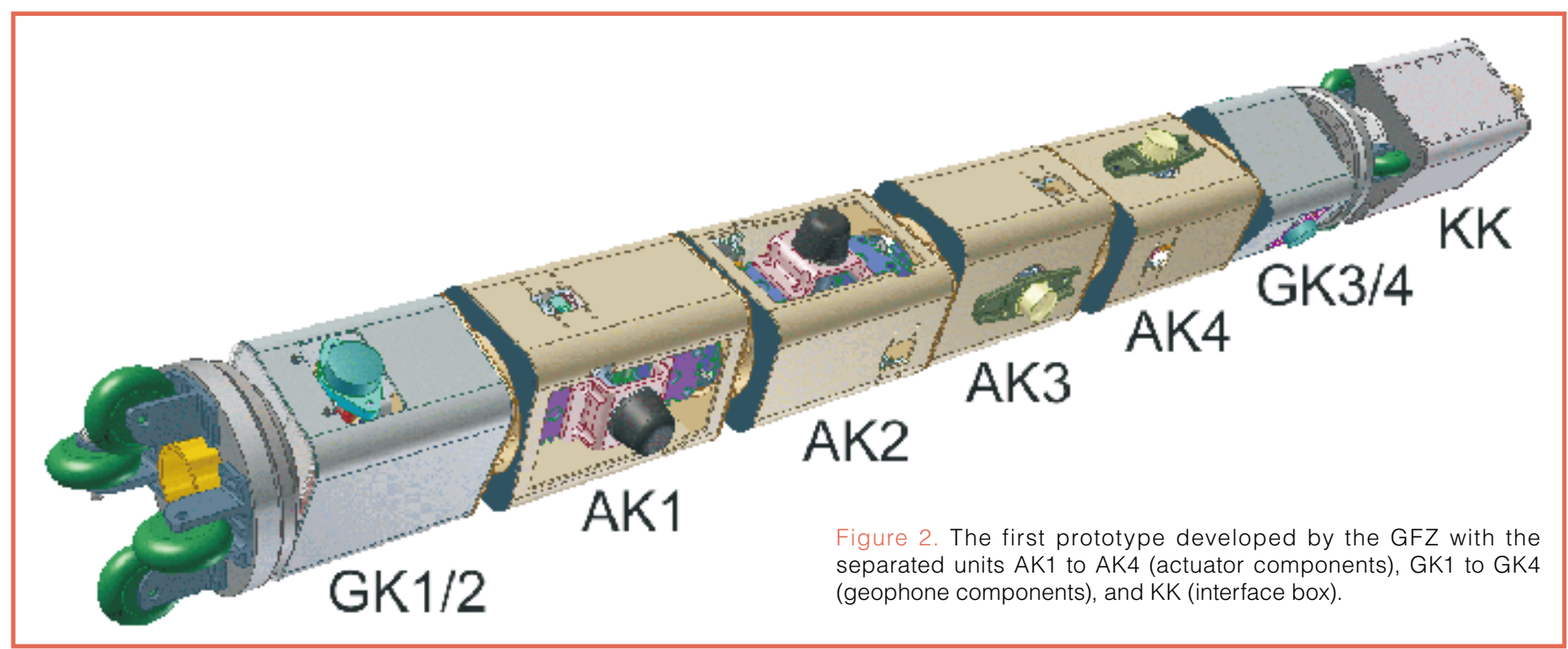

The receivers used are four 3-component geophones integrated in two geophone units (GK1/2 and GK3/4; Fig. 2) with each 3-component geophone mounted in opposite alignment. Again, the geophone units can be rotated in $15^{\circ}$ increments perpendicular to the borehole axis. This allows receiving the seismic response from the surrounding rock in defined space directions adjusted to the actuator positions.

The data logger unit (KK; Fig. 2) includes the interface with the external feed cables and the data logger which is used for source activation, triggering, and seismic data acquisition. Additionally, a sensor for inclination, a compass, and an odometer are integrated to determine the position and orientation of the SPWD device in the borehole. An infrared camera at the top monitors the borehole wall.

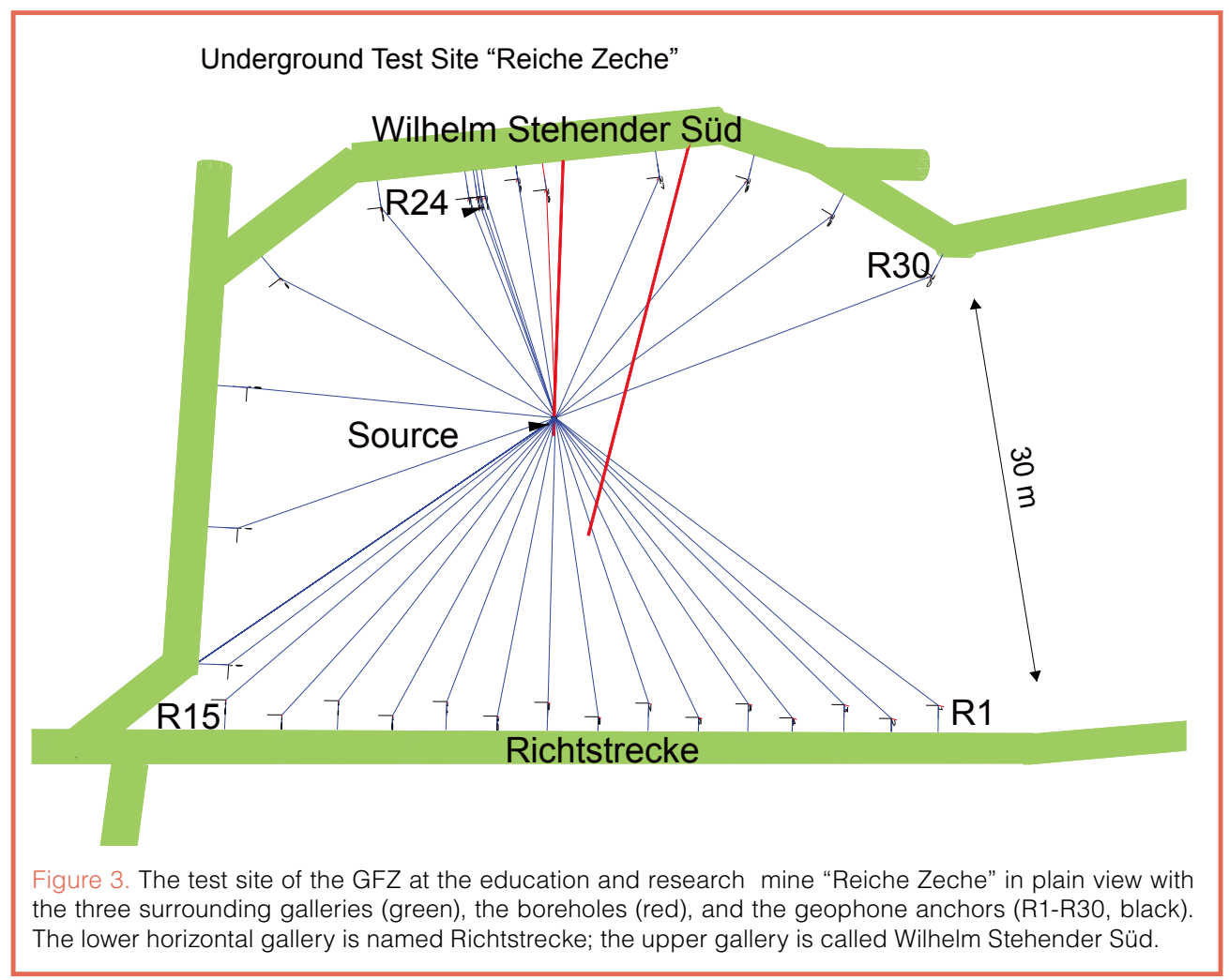

Several guide rollers are mounted at the top and the end to move the prototype slightly in the borehole. In order to take measurements, the actuators and geophones must be pressured radially to the borehole wall. The prototype is automatically centered in the borehole. The actuators are decoupled from the prototype body so that all seismic energy is initiated exclusively in the borehole wall.

The actuators are controlled in amplitude and phase. Acceleration sensors are integrated in the front stamps of the actuators to measure the emitted seismic signals. With respect to a specific radiation pattern, the signal for each actuator is calculated based on the local coupling conditions at the borehole wall and then applied.

\section{Test Environment}

A test site in the education and research mine "Reiche Zeche" in Freiberg, Germany (Wenke et al., 2010) has been constructed to ensure constant environmental conditions. Surrounded by three galleries, the site comprises a block of homogeneous high-grade gneisses of almost $50 \mathrm{~m}$ x $200 \mathrm{~m}$. Previously used as a test site for seismic sources and receivers of an integrated seismic imaging system (Giese et al., 2006), the site has been expanded. Over thirty 3-component geophone anchors one or two meters long are installed around the area about 4-9 m apart (Fig. 3). 
Two horizontal boreholes of $20 \mathrm{~m}$ and $30 \mathrm{~m}$ length were drilled towards a gallery to test the prototype. Diamond coring was applied to yield both high-quality cores and true-to-size caliber. The latter was only disrupted at two centimeter-sized fracture zones which appear to pass through the whole rock block and which are filled with quartz, feldspar, clay, and fluids. The dike-like fault zones and the galleries act as well-defined reflectors for the borehole seismic measurements.

\section{Seismic \\ Measurements}

Several measurements

were implemented during the first year to test the functionality of the different units of the prototype (e.g., the pneumatic contact pressure and the handling of the prototype with rods in the borehole). The performance of the actuators was examined to adapt the parameters of the sweep signals and to maximize the energy of the seismic source in order to reach a sufficient exploration range.

To achieve a directional radiation effect it is essential that all four actuators can be controlled independently of each

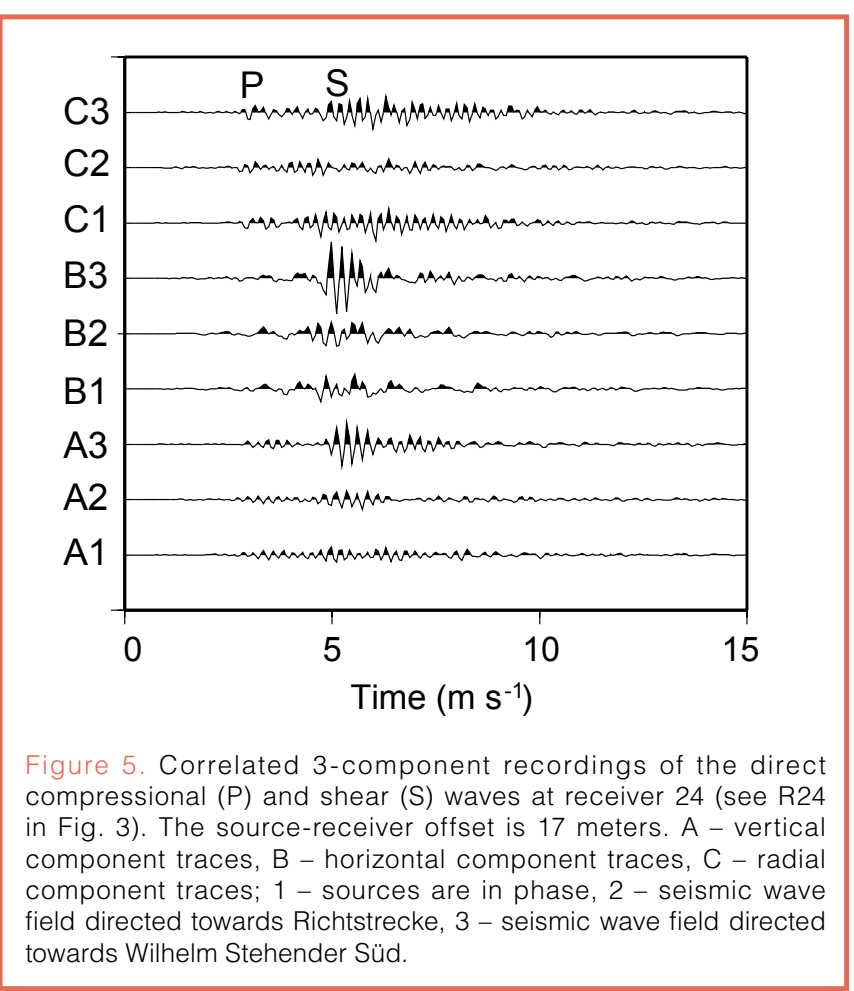

other. An increased radiation of seismic wave energy in the direction of the borehole axis allows the view in areas to be drilled. Therefore, every actuator related to amplitude and phase of the source signal must be controlled. The next step for focusing the seismic waves is to use the method of phased array, which has been developed in material sciences and for medical diagnostics by sonography (Hedrick and Hykes, 1996). The signal phases for each actuator can be determined depending on the seismic wave velocities of the surrounding rock, the distance of the actuators to each other, and the frequencies used. Furthermore, the influence of the seismic velocity on the radiation pattern was studied by applying a sonic log with the actuators with a broad frequency band (1-14 kHz).

The influence of different seismic source arrangements was investigated in order to achieve the directional characteristics. The main goal of the measurements was to focus the initiated seismic waves in the direction of the borehole axis.

\section{Results}

The borehole data overall show a good signal-to-noise ratio. The direct seismic wave field indicates distinct compression and shear waves (Fig. 4). As expected, the anisotropic gneisses cause shear wave splitting of about ten percent. The quality of the seismic data in amplitude and frequency spectra correlates strongly with the fracture density of the rock along the borehole, which was determined with an optical borehole scan and on core. These regions are associated with a lower signal-to-noise ratio. Independent of the local rock conditions, the borehole data show seismic 
reflections from ahead and rearwards. In particular the reflections from the gallery ahead are used for the calibration of focusing.

Analysis of several seismic measurements with a focus on the direct seismic waves shows that the phased array technology influences explicitly the directional characteristics of the radiated seismic waves. Their amplitudes can be enhanced three times more in the desired direction and can simultaneously be attenuated in the reverse direction. Figure 4 and 5 present a set of exemplary data recorded at the receiver in geophone anchor R24 (Fig. 3). The source is positioned close to the bottom of the borehole. The frequency content of the source signal is between $500 \mathrm{~Hz}$ and $5000 \mathrm{~Hz}$. $\mathrm{P}$-waves arrive at about $3 \mathrm{~ms}$ and S-waves at $4.8 \mathrm{~ms}$, corresponding to seismic wave velocities of $5700 \mathrm{~m} \mathrm{~s}^{-1}$ and $3500 \mathrm{~m} \mathrm{~s}^{-1}$, respectively. The amplitudes of the P-wave are highest on the radial component (C in Figs. 4 and 5) directed to the source. The amplitudes of the S-wave are highest perpendic-ular to the P-wave on the vertical (A) and horizontal component (B). If the source wave field is directed towards the gallerie "Wilhelm Stehender Süd" (Fig. 3), the amplitude of the S-wave is clearly amplified (B3 and C3) in comparison to source signals without manipulation of wave field direction (B1 and $\mathrm{C} 1$ ). A slight increase of P-wave amplitudes can also be observed in the radial component in $\mathrm{C} 3$ compared to $\mathrm{C} 1$. If the wave field is directed towards the gallery "Richtstrecke" (Fig. 3), the amplitude decreases slightly on the radial component $\mathrm{C} 2$ compared to original source wave field in $\mathrm{C} 1$, whereas no significant reduction of amplitudes is observed on the vertical (A2) and horizontal (B2) components.

\section{Conclusions}

The application of the phased array technology for the directional investigation of borehole surroundings is very promising. However, focusing of the seismic waves has to be improved to maximize the energy in the desired direction. For that purpose several measurements and modeling of different source and receiver configurations must be done to calibrate the initiated seismic signals of the sources. The application of a phased array source system influences the processing and imaging of the data. Methods developed for surface seismic and VSP measurements have to be adapted to take advantage of the improved data quality and known directional information of the recorded wave field.

The next step will be the development of a wireline SPWD prototype for vertical boreholes with depths to $2000 \mathrm{~m}$. Modifications in the arrangement of the different units will be necessary, as well as an adaptation to fluid-fill under the conditions in deep boreholes with respect to pressure and temperature. If the wireline prototype tests successfully, we plan to implement the tool into the downhole assembly of a drill string as a Logging-While-Drilling tool. This would allow a seismic prediction of structures or faults while drilling and will help to reduce risks encountered while drilling.

\section{Acknowledgements}

We are grateful for support from the technical team of the "Reiche Zeche" for the preparation of the test site and from our partners in the SPWD project, the TU Bergakademie Freiberg, GeoThermal Engineering GmbH, and Herrenknecht Vertical GmbH. The project (S)PWD ((Seismic) Prediction While Drilling) is funded by the German Federal Environment Ministry, BMU.

\section{References}

Giese, R., Dickmann, Th., Eppler, Th., and Lüth, S., 2006. Seismic tomography to investigate the tunnel surroundings of the Side Gallery West of the multifunctional station Faido. In Löw, S. (Ed.), Geologie und Geotechnik der Basistunnels am Gotthard und am Lötschberg, Tagungsband zum Symposium Geologie Alptransit, Zürich (vdf Hochschulverlag an der ETH), 145-154.

Hedrick, W.R., and Hykes, D.L., 1996. Beam steering and focusing with linear phased arrays. J. Diagn. Med. Sonogr., 12:211-215.

Wenke, A., Giese, R., Jaksch, K., Kopf, M., Kreuter, H., Reich, M., Reinhardt, J., and Sohmer, M., 2010. (S)PWD - (Seismic) Prediction While Drilling: Development of a new high-resolution Seismic While Drilling (SWD) concept for geothermal drilling. Proceedings World Geothermal Congress, Indonesia, 25-29 April 2010.

\section{Authors}

Katrin Jaksch, Helmholtz Centre Potsdam - GFZ German Research Centre for Geosciences, Scientific Drilling, Telegrafenberg, F 358, D-14473, Potsdam, Germany, e-mail: kawi@gfz-potsdam.de.

Rüdiger Giese, Matthias Kopf, Andreas Jurczyk, Stefan Mikulla, Stefan Weisheit, Marco Groh, Kay Krüger

Helmholtz Centre Potsdam GFZ German Research Centre for Geosciences, Scientific Drilling, Telegrafenberg, D-14473, Potsdam, Germany. 